\title{
Multimedia Tools for Teaching Basic Electronics
}

\author{
Doyce Tesoro-Martinez ${ }^{1}$, Tomas U. Ganiron $\mathrm{Jr}^{2}$ and Harold S. Taylor ${ }^{3}$ \\ ${ }^{1}$ Department of Chemical and Materials, University of Auckland, Auckland, NZ \\ ${ }^{2}$ Railway Technical Society of Australasia (RTSA), Wellington, NZ \\ ${ }^{3}$ Department of Computer Engineering, Victoria University of Wellington, NZ \\ 1doycetesoro@gmail.com, ${ }^{2}$ tomasuganironjr@gmail.com, \\ ${ }^{3}$ haroldtaylor1113@gmail.com
}

\begin{abstract}
This paper presents the application of interactive multimedia courseware for teaching rectifiers in electrical engineering and electronics engineering courses. The aim of the study is to present a learning innovation using courseware on rectifier as an additional tool in teaching and studying EE 432 (Power Electronics) for Spring Semester of 2013-2014. The courseware was developed using Macromedia Authorware as the authoring language. Students gain hands-on experience, and also improve their skill in product development, selfdirected learning, teamwork, and project management. Practical projects increase the challenge for students and, hence, their interest level. Graphics and animations are used to give a more attractive and effective presentation. The courseware developed is also capable of producing graph simulation which agreed with the simulation using MATLAB program. Using this courseware the teaching and studying process will be more effective, attractive and interesting.
\end{abstract}

Keywords: Learning strategies, multimedia, teaching technologies

\section{Introduction}

Multimedia can be defined as a seamless integration of text, sound, images of all kind and control software within a single digital environment. The multimedia technology has made tremendous impact in the education sector. Many multimedia coursewares have been developed as additional tools to assist the teacher and the student to have a better understanding of a subject. It is the multimedia technology that made virtual universities a reality [1].

Many institutions and organizations are finding out first-hand the benefits of multimedia learning. Engineering subjects which is being taught the conventional way can greatly benefit using multimedia courseware as a medium to teach the subjects [2, $16,17]$.

Realizing this fact, a multimedia courseware was developed for the topic on rectifiers. This paper deals with the development of the courseware. This paper will explain the processes involved in the production of the courseware.

\section{Related Literature}

Several theories of learning have examined the dual coding of verbal communication, including visual, auditory, or articulatory codes, and nonverbal communication, which may include shapes, sounds, kinesthetic actions, and emotions. The theories have been 
linked to multimedia and the research has tested various classroom applications. This section briefly summarizes pertinent findings for the use of videos.

Over the past decade a corpus of studies has accumulated that investigates the effects of multimedia strategies on learning. Multimedia typically refers to the presentation of material in two forms: auditory/verbal and visual/pictorial [3]. The strategies have included PowerPoint [4], games [5], and computer-assisted video learning [6] in a variety of content areas, in addition to auditory and video media.

In [7], cognitive theory of learning is activated through five steps: - (a) selecting relevant words for processing in verbal working memory, (b) selecting relevant images for processing in visual working memory, (c) organizing selected words into a verbal mental model, (d) organizing selected images into a visual mental model, and (e) integrating verbal and visual representations as well as prior knowledge [6,7] His theory represents an amalgam of Sweller's [9] cognitive load theory.

The results of Mayer's research indicate that the contiguous presentation of verbal and visual material as in videos with integrated dialogue or narration is most effective for novices and visual learners $[10,11]$. That is, the use of meaningful video clips in teaching may be most appropriate for introductory courses, introducing complex topics in any course, lower achieving students, and visual/spatial learners. Certainly, all other topics and students may benefit as well.

The empirical findings of research on the effectiveness of videos embedded in multimedia classes or modules are very encouraging. Numerous studies in specific areas such as teacher education have produced significant results favoring videos [12]. However, research in other areas is sparse. Over the past four decades most studies have concentrated in the mental and physical health fields, especially psychology and psychiatry, counseling, and medicine. The only other areas that received moderate attention are political science and management/leadership.

\section{Application Development}

\subsection{Multimedia Components}

Multimedia learning consists of two important components, the hardware and the software. The hardware and software must be compatible with each other in order to produce the desired results $[12,13]$. The hardware is the component that will be used to develop, store and present the courseware.

3.1.1. Hardware: Hardware plays an important role in the development of multimedia presentations. A personal computer with multimedia capabilities is needed to support the preparation and presentation of the multimedia. The basic elements that makes up the multimedia computer is a processor capable of supporting audio and video, interactions tools such as keyboard and mouse, screen for displaying text, graphics and images, speakers and microphones, playback devices such as the CD-ROM to access recorded materials $[13,14]$. Table 1 shows the specification of a multimedia computer as specified by the Multimedia PC Council. 
Table 1. Multimedia Computer Specification

\begin{tabular}{|l|l|}
\hline $\begin{array}{l}\text { Technical } \\
\text { requirements }\end{array}$ & Specification \\
\hline Processor & $25 \mathrm{MHz} 486 \mathrm{SX}$ \\
\hline Memory & $4 \mathrm{MB}$ \\
\hline Hard disk & $160 \mathrm{MB}$ \\
\hline Display & $640 \mathrm{x} 480,65,536$ colours \\
\hline Sound & $\begin{array}{l}\text { 16-bit digital,MIDI playback, 8 note } \\
\text { synthesizer }\end{array}$ \\
\hline $\begin{array}{l}\text { CD - ROM } \\
\text { drive }\end{array}$ & $\begin{array}{l}\text { 300KB/s sustained transfer rate, max } \\
\text { average seek time 400 milliseconds, } \\
\text { CD-ROM XA ready, multisession } \\
\text { capable }\end{array}$ \\
\hline
\end{tabular}

3.1.2. Software: The software is the interfacing medium between the courseware developer and the hardware. In multimedia presentation the software is required capture text, images, sounds, animations in a single digital environment. The software that does this is called the authoring software [15].

The authoring software chosen to develop the courseware is Macromedia Authorware 6.0. This software was chosen because of the following factors: a) Easy to learn. All contents are kept inside an icon and there is no complex programming; b) Crossplatform compatibility; c) Icon based flowchart allows program structure to be seen. There is no need for complex programming knowledge to operate the software; c) Supports animation developed in Macromedia Director and Macromedia Flash; d) Supports GIF animations and e) Ease of troubleshooting errors in program.

\subsection{Courseware Development}

The development of the courseware can be divided into four stages. The four stages are planning, design, building and evaluation.

3.2.1. Planning: The software is the interfacing medium between the courseware developer and the hardware. In multimedia presentation the software is required capture text, images, sounds, animations in a single digital environment. The software that does this is called the authoring software [14, 15, 18]. This is the initial stage in any multimedia presentation development. In this stage the need for a multimedia courseware is identified while the mission and objective of the courseware was defined. The mission and objective statement is important as it will act as guide in the development process and also will be use a benchmark in evaluating the final product. The target group for the courseware is also defined in this process. It is important that the courseware developed delivers the information to the target group. Apart from these the planning process also includes the following: a) Identifying the problems; b) Finding solution to the problems; c) Deciding on the design objective; d) Deciding and choosing the content for the courseware; e) Deciding on the suitability of the courseware design and e) Deciding on the time and cost needed to develop the courseware.

The planning process can be compared to a road map that gives direction that need to be taken. It is vital that the planning process is given extra attention. 
3.2.2. Design: This second stage covers the following sections [15]: (a) Implementation-this is where the developer decides on the type of metaphor to be used. Among the usual metaphors that can be used is designing the courseware like a book, a lab experiment or a classroom environment. The type of graphics that will be used is decided at this stage. (b) Decision on the specification-the specification of the courseware had to be defined. This is important that the courseware is not too sophisticated and is accessible to the target group. (c) Functionality-a courseware need to be user friendly and the level of interactivity used is paid attention in this stage.

3.2.3. Building: This is the stage where the real work is done. The contents of the courseware is collected and integrated into a single environment. The contents of the courseware might be from books, internet, digital camera or other sources. The integration of the contents is done using the authoring software. This is the stage that determines the success of the courseware.

3.2.4. Testing and Evaluation: The software is the interfacing medium between the courseware developer and the hardware. In multimedia presentation the software is required capture text, images, sounds, animations in a single digital environment. The software that does this is called the authoring software $[12,14]$.

This is the last stage of the development process. Copy of the courseware is distributed to certain parties to be evaluated upon. The feedback received will be considered and the modification is made. There are formative evaluation where the evaluations is done during the design of the courseware and summative evaluation where the courseware is evaluated after the building process.

\subsection{Contents of the Courseware}

The general contents of the software can be divided as shown in Figure 1.

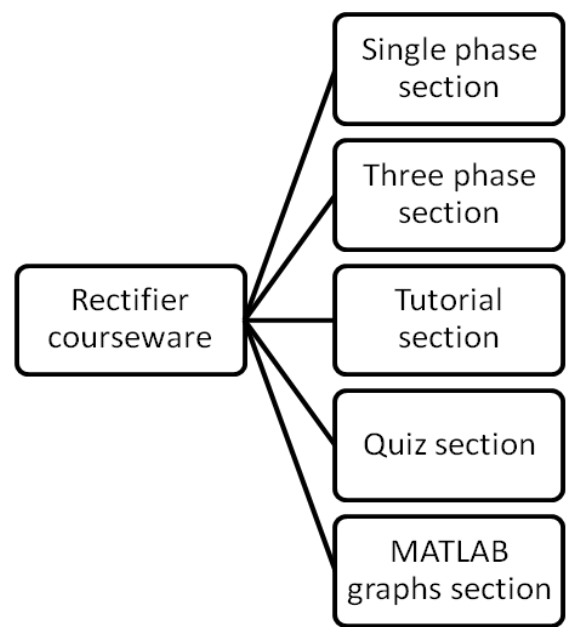

Figure 1. General Contents of the Courseware

3.3.1. Single Phase Section: This section can be further divided into sub-sections as shown in Figure 2. The uncontrolled sections contain principle of uncontrolled single phase rectifiers. The controlled section deals with the single phase controlled rectifiers. Both these sub sections can be divided into four modules namely half wave, full wave, 
examples and progress chart. The function of the progress chart is to monitor the progress of the user.

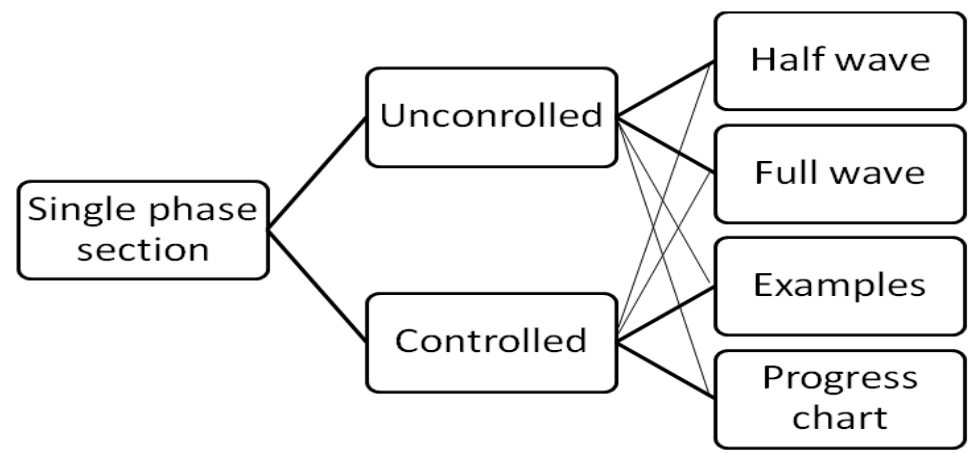

Figure 2. Single Phase Section Contents

3.3.2. Software: This section can be divided into sub-sections as shown in Figure 3 . The introduction section contains some introduction about three phase rectifiers. The topics section contains the three phase rectifier topics. The examples section contains examples on three phase rectifiers and the progress chart keeps track on the user's progress.

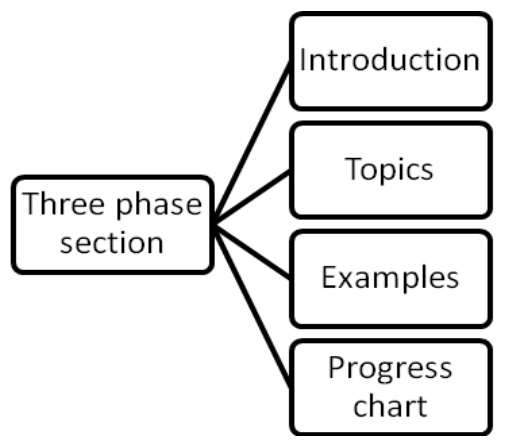

Figure 3. Three Phase Section Contents

3.3.3. Tutorial Section: This section can be further divided into sub-sections shown in Figure 4. The review questions section contains short questions which can be printed out and answered. The assignment section contains questions that need some calculation. These questions can be printed out.

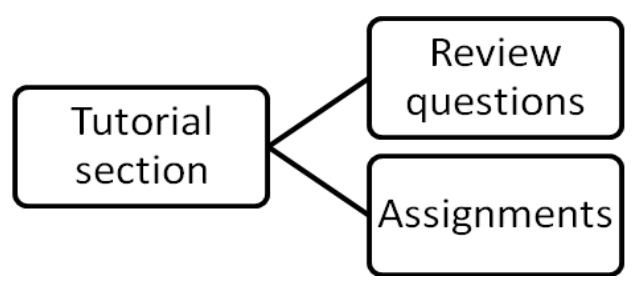

Figure 4. Tutorial Section Contents 
3.3.4. MATLAB Graph Section: This section contains the rectifier graphs that were produced using MATLAB simulation. Sample of the graph produce is shown in Figure 5 .
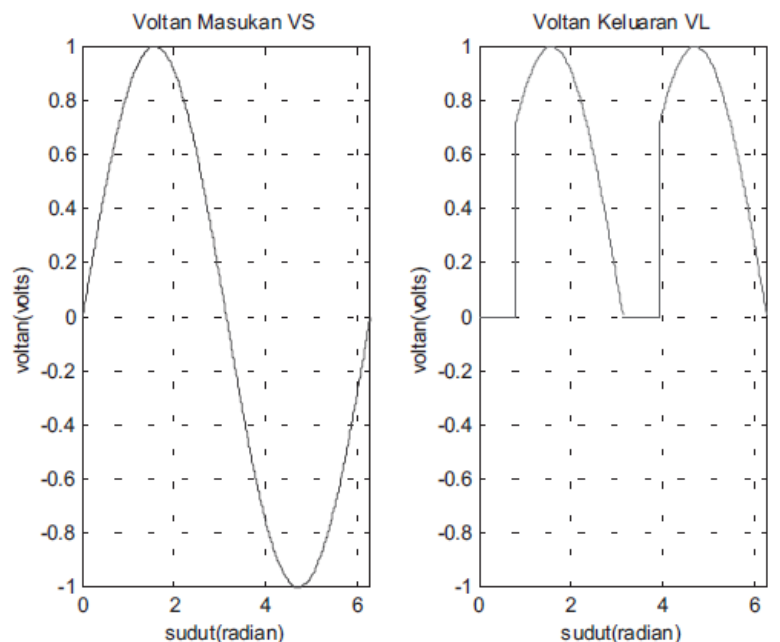

Figure 5. Output Voltage for Full Wave Single Phase

\section{Results}

The finished product of this courseware which is published in compact disk medium can be executed from any personal computer using the windows operating system be it a desktop or a laptop. When the courseware is first loaded a start page will appear as shown in Figure 6.

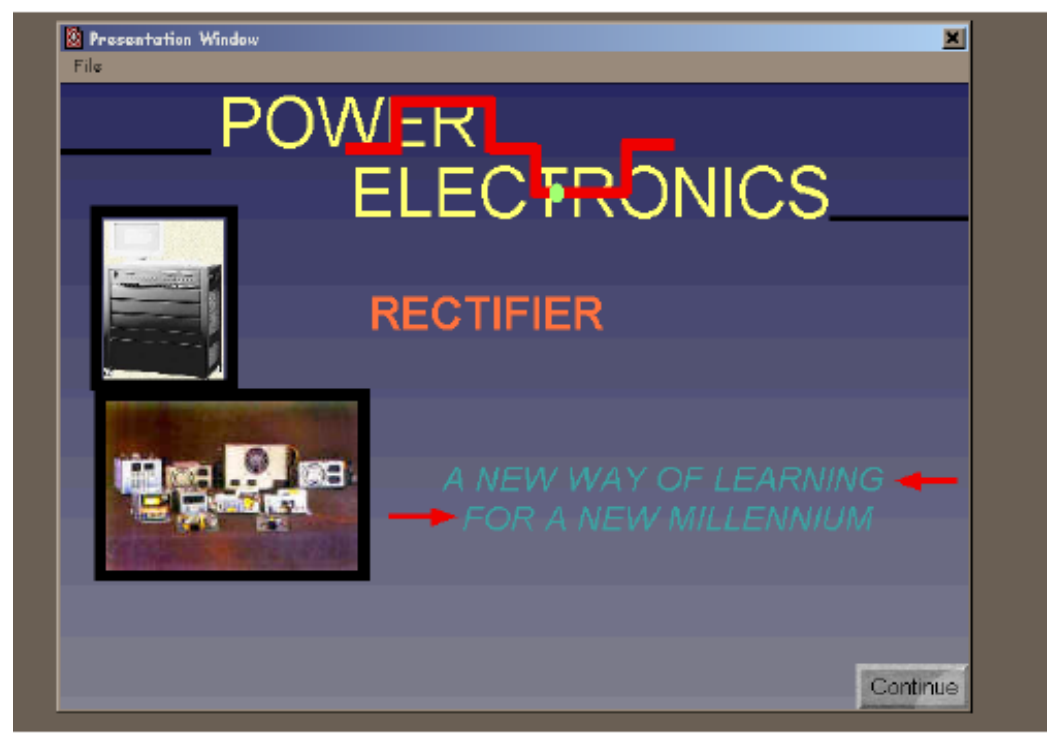

Figure 6. Application Menu Page

Clicking on the Continue button will take the user to the name register page where the user will be asked to enter his or her name. This is shown in Figure 7. 


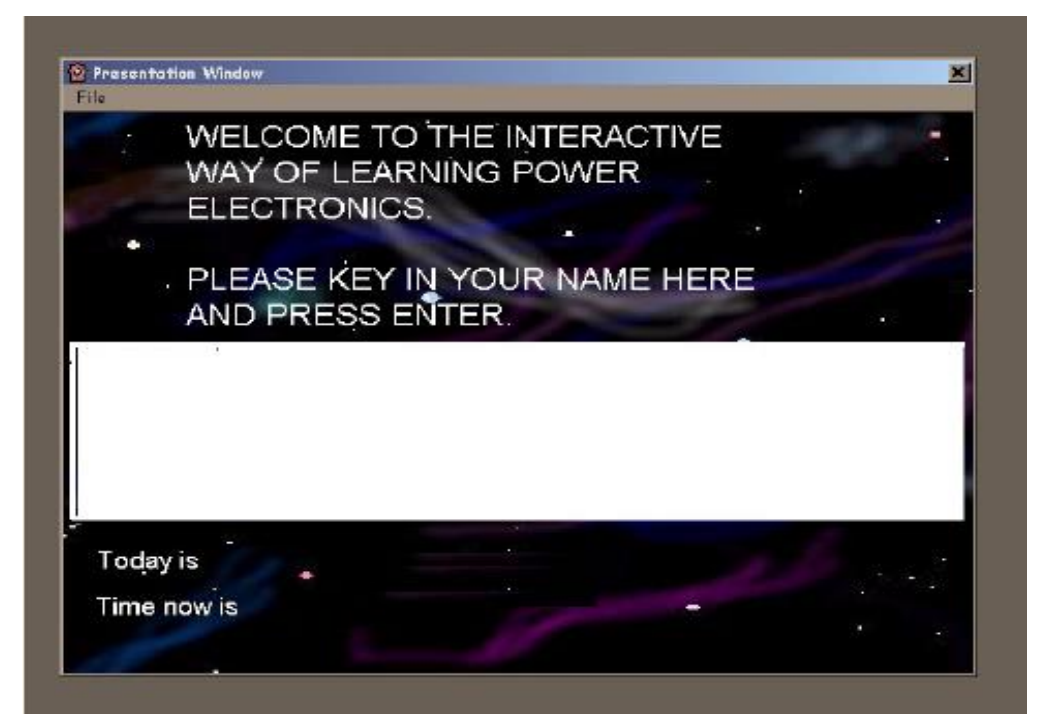

Figure 7. Name Register Page

After the user has entered his or her name, the name will be registered. The next page that will emerge is the welcoming page showing the name of the previous users and the also the date and time the applications was last used. This page is shown in Figure 8.

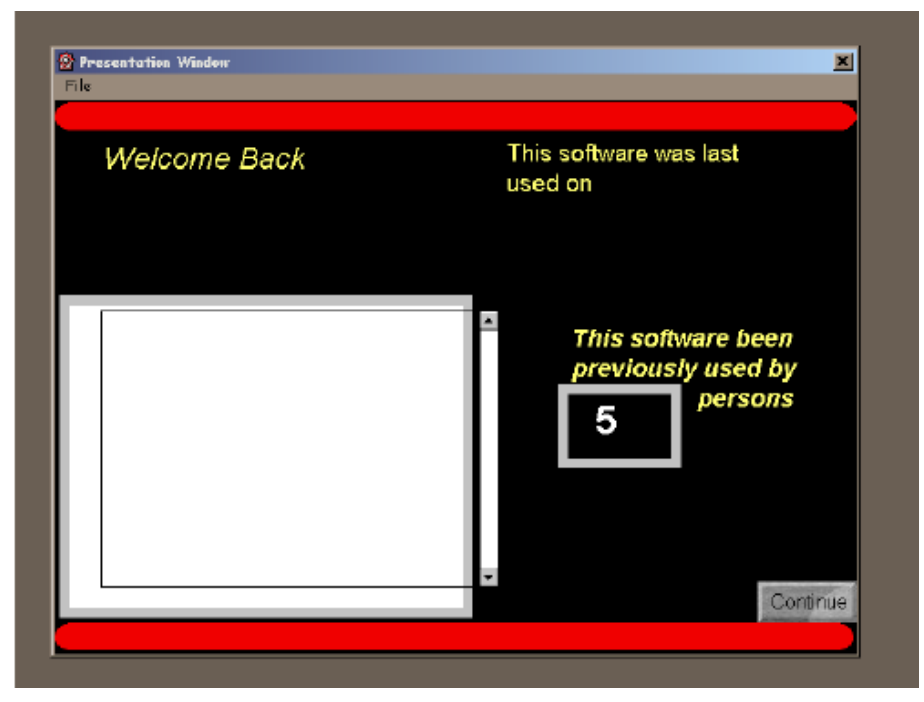

Figure 8. Welcome Page

Clicking on the continue button will take the user to the introductory page as shown in Figure 9. 


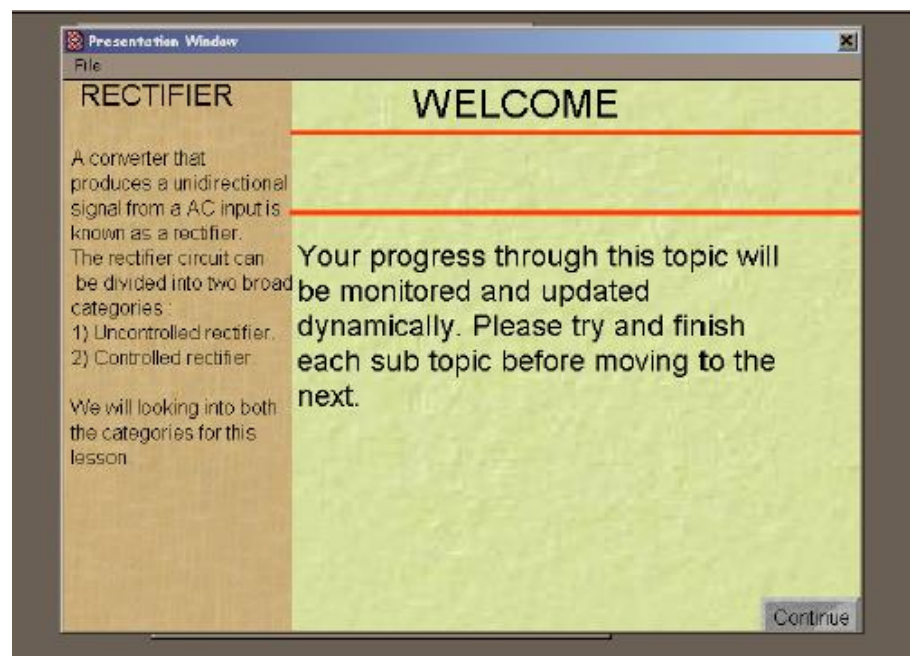

Figure 9. Introductory Page

Clicking the continue button will take the user to the Main Menu page. This is the main page and this page contains six buttons such as single phase, three phase, tutorial, project, quiz and MATLAB graphs. This is shown in Figure 11.

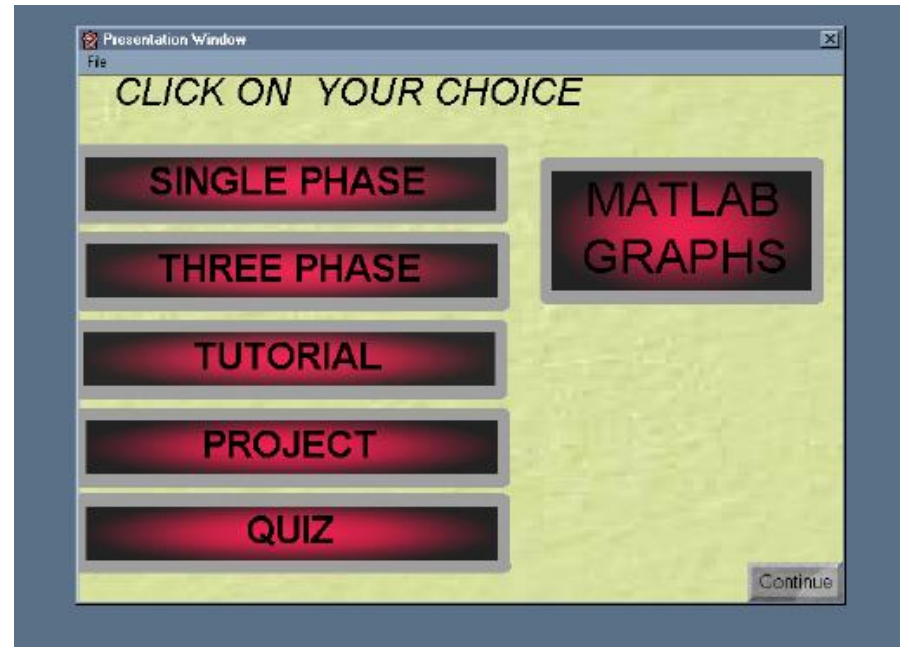

Figure 10. Main Menu Page

Clicking on the desired topics will take the user to the page containing those topics. This topic contains many more sub topics and this courseware contains more than 200 icons that are integrated. Figure 11 shows the main page of these topics. 


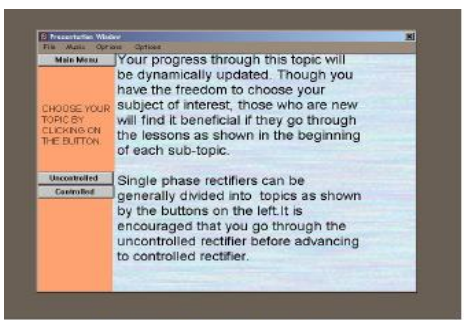

Single phase main page

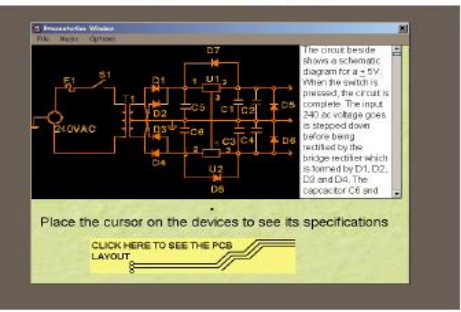

Project main page

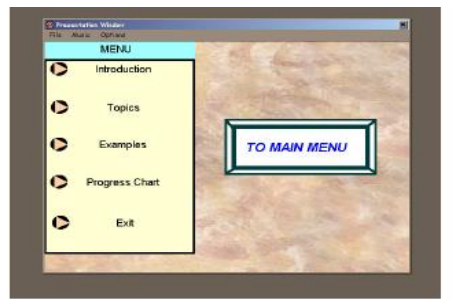

Three phase main page

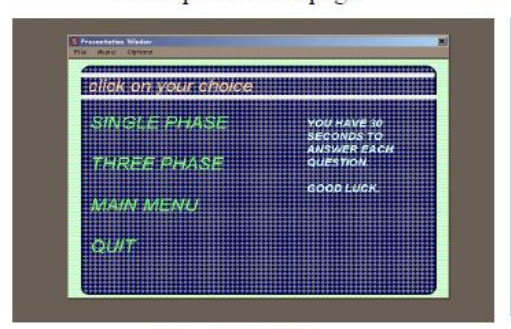

Quiz main page

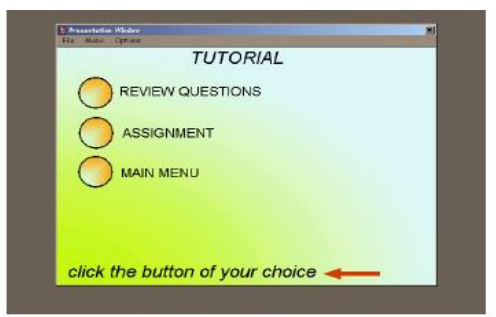

Tutorial main page

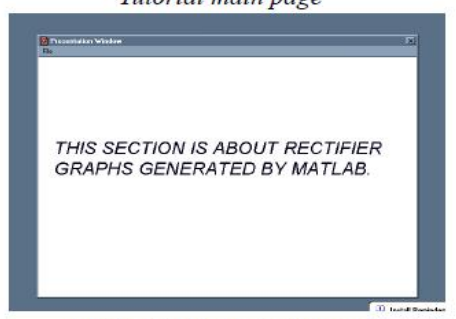

MATLAB Graphs main page

\section{Figure 11. Main Page Topics}

Sample of the MATLAB simulation output graphs are shown in Figure 12 for the single phase applications of the rectifier. The simulated result for the required firing angle can be obtained through the learning tools just by changing the required value in the window.

The courseware is accompanied by multimedia effect such as music and animation that will enhance the learning process. There are also graphics that will help to make the learning process much more interesting. Apart from buttons there are also many other type of interactivity such clicking on objects, keypress, and 'hot spots'.
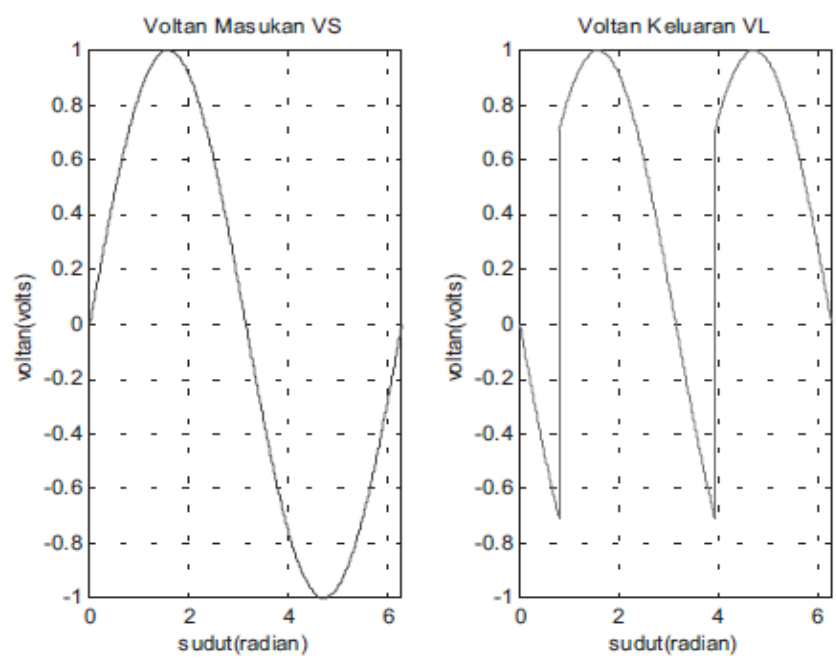

\section{Figure 12. Single Phase Output Voltage Graph}

\section{Conclusion}

The rectifier courseware was successfully developed and can be used by lecturers and students in universities, distance learning centers and other institutions. The courseware which is dynamic increases the attention span of the students by using physical interaction. This courseware also allows flexible scheduling and it is step towards making education 
flexible and affordable. The final product of the courseware is published in $\mathrm{CD}$ medium which makes it much easier to distribute compared to books. It is found that the simulated waveform produce by the Authorware media are agreeable with the theoretical and also from MATLAB program.

This courseware is the first multimedia application at USM for teaching electrical power and can be further expanded. With the ever increasing powers of the personal computers and multimedia authoring softwares an even more dynamic and attractive application can be developed.

\section{References}

[1] N. Djuric, M. Prsa and K. Kasas-Lazetic, "Information Network for Continuous Electromagnetic Fields Monitoring”, International Journal of Emerging Sciences, vol. 1, no. 4, (2011).

[2] P. Bauer, "Distance Practical Education for Power Electronics", International Journal of Engineering Education, vol. 23, no. 6, (2007).

[3] T. U. Ganiron Jr., "Planning and Execution of Holistic Model Using Object Oriented Technology", Proceedings of the 3rd International Conference The Future Education, (2013) June 7, Florence, Italy.

[4] T. Ganiron Jr., "Accelerated Learning Techniques: Teaching Critical Thinking in Qassim University", Journal of Proceedings of the 41st Annual Conference of the European Society for Engineering Education, (2013) September 16, Leuven, Belgium.

[5] R. H. Hong, D.C. Lu and S. Sathiakumar, "Project-Based Laboratory Teaching for Power Electronics and Drives", IEEE Transactions on Education, vol. 51, no. 1, (2008).

[6] T. Ucol-Ganiron Jr., "Cultural Learning Environment and Perception of Structural Engineering Classes in Qassim University", WSEAS Transactions on Advances in Engineering Education Journal, vol. 9, no. 3, (2012), pp. 84-93.

[7] T. Ucol-Ganiron Jr., "Student Competencies in Structural Engineering: Modelling Cultural Environment in Qassim University", Journal of Proceedings of the 40th Annual Conference of the European Society for Engineering Education, (2012) September 23-26, Thessaloniki, Greece.

[8] P. Bauer and V. Fedak, "Educational Visualization of Different Aspects for Power Circuits and Electrical Drives", $11^{\text {th }}$ International Power Electronics and Motion Control Conference, vol. 4, (2004).

[9] T. Ucol-Ganiron Jr., "Web-Enhanced Project Management Course", International Journal of u- and e- Service, Science and Technology, vol. 6, no. 1, (2013), pp. 49-59.

[10] S. Toral, "Implementation of a Web-Based Educational Tool for Digital Signal Processing Teaching using the Technological Acceptance Model", IEEE Transactions on Education, vol. 48, no. 4, (2005).

[11] V. Fedak and P. Bauer, "E-learning in Education of Electrical Drives and Power Electronics: Opportunities and Challenges", Proceedings of the $15^{\text {th }}$ International Conference on Electrical Drives and Power Electronics, (2005).

[12] T. U. Ganiron Jr., "The Effect of Study Group Activity Guide in Expository Reading and Writing Course at the College of Architecture in Qassim University”, International Journal of Education and Learning, vol. 3, no. 1, (2014) March, pp. 23-34.

[13] J. Marcos, "E-Learning System for Power Electronics Converters", Power Electronics Specialists Conference, (2006).

[14] T. Ucol-Ganiron Jr, and A. Alaboodi, "Cultural Learning Environment in Structural Engineering Courses of Architecture and Civil Engineering Students in Qassim University", Procedia-Social and Behavioral Sciences, vol. 102, (2013), pp. 300-310.

[15] T. Ucol-Ganiron Jr., A. Alaboodi and A. Eltoumi, "Designing and Developing a Web Enhanced Project Management Course for Engineering Graduating Students", Journal of Proceedings of the International Forum on Engineering Education, (2010) November 23-25, University of Sharjah, United Arab Emirates.

[16] T. U. Ganiron Jr., "Applications of Accelerated Learning in Teaching Environmental Control System in Qassim University", International Journal of Education and Learning, vol. 2, no. 2, (2013), pp. 27-38.

[17] T. U. Ganiron Jr., "Teaching Styles of using English Drama in Critical Thinking Course for Architecture Students in Qassim University", International Journal of Education and Learning, vol. 3, no. 4, (2014) September, pp. 23-34.

[18] T. Kowalska and M. Kamiński, "Adaptive Neurocontrollers for Drive Systems: Basic Concepts, Theory and Applications", Advanced and Intelligent Control in Power Electronics and Drives. Springer International Publishing, (2014), pp. 269-302. 


\section{Authors}

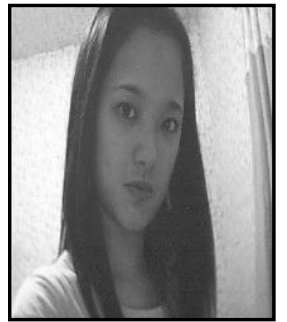

Doyce Tesoro-Martinez, she was born in San Fernando, La Union. She received both BS and MS Chemical Engineering from De La Salle University, Manila in 2000. Ms. Tesoro-Martinez has been pursuing research in electronics education, fluidized web technology and waste treatment plant, She has published over 30 referred papers in relevant journals and conferences, which majority focus on the areas of manufacturing engineering and e-fluidized.

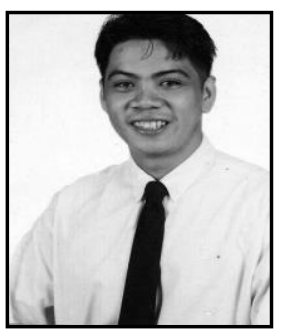

Tomas U. Ganiron Jr., he obtained his Doctor of Philosophy in Construction Management at Adamson University (Philippines) in 2006, and subsequently earned his Master of Civil Engineering major in Highway and Transportation Engineering at Dela Salle UniversityManila (Philippines) in 1997 and received Bachelor of Science in Civil Engineering major in Structural Engineering at University of the East (Philippines) in 1990. He is a registered Civil Engineer in the Philippines and Professional Engineer in New Zealand. He has received the Outstanding Civil Engineer in the field of Education given by the Philippine Media Association Inc. (1996), ASTM Award CA Hogentogler (2008) by IPENZ in New Zealand and Outstanding Researcher (2013) in Qassim University, Buraidah City.

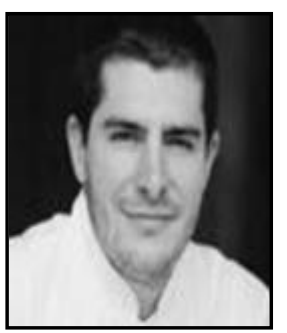

Harold S. Taylor, he received the BS Civil Engineering degree at University Canterbury in 1983 and earned his MS (1985) and $\mathrm{PhD}$ (1987) degrees in Civil Engineering at University of Auckland. He has published several research papers in national and international journals in the area of hydrology, water resources engineering, waste treatment plant and river engineering. He has also authored books viz, Ocean Engineering, River and Sediments, Water Resources and Engineering, and Fluid Mechanics Students' Handbook. 
International Journal of Education and Learning Vol.3, No.2 (2014) 